\title{
Otology
}

\section{Retrosigmoidal placement of an active transcutaneous bone conduction implant: surgical and audiological perspectives in a multicentre study}

\author{
Posizionamento retrosigmoideo di una protesi transcutanea attiva a conduzione \\ ossea: prospettive chirurgiche e audiologiche in uno studio multicentrico
}

\begin{abstract}
Pietro Canzi ${ }^{1 *}$, Irene Avato ${ }^{1,2 *}$, Millo Beltrame ${ }^{1 *}$, Giovanni Bianchin ${ }^{3}$, Marco Perotti ${ }^{4}$, Lorenzo Tribi ${ }^{3}$, Barbara Gioia ${ }^{4}$, Federico Aprile ${ }^{1}$, Stefano Malpede ${ }^{1}$, Andrea Scribante ${ }^{5}$, Marco Manfrin ${ }^{1}$, Marco Benazzo ${ }^{1}$

'Department of Otorhinolaryngology, University of Pavia, Foundation IRCCS Policlinico "San Matteo", Pavia, Italy; ${ }^{2}$ PhD in Experimental Medicine, University of Pavia, Italy; ${ }^{3}$ Department of Otolaryngology and Audiology, Arcispedale Santa Maria Nuova IRCCS, Reggio Emilia, Italy; ${ }^{4}$ Otorhinolaryngology Unit, Ospedale Civile "SS Antonio Biagio and C. Arrigo", Alessandria, Italy; ${ }^{5}$ Unit of Orthodontics and Paediatric Dentistry-Section of Dentistry-Department of Clinical, Surgical, Diagnostic and Paediatric Sciences, University of Pavia, Pavia, Italy

${ }^{*}$ P. Canzi, I. Avato and M. Beltrame contributed equally to this work
\end{abstract}

\begin{abstract}
SUMMARY
Introduction. The retrosigmoidal (RS) placement of the Bonebridge system (BB) has been advocated for cases of unfavourable anatomical or clinical conditions which contraindicate transmastoid-presigmoidal positioning. However, these disadvantageous conditions, combined with the considerable dimensions of the implant, may represent a challenge, especially for surgeons with no skull base experience. Moreover, the literature reports only limited experience concerning RS implantation of the BB system.

Methods. A multicentre, retrospective study was conducted to analyse the surgical and functional outcomes of a wide population of patients undergoing RS placement of the BB system by means of a surgical technique specifically developed to overcome the intraoperative issues related to this surgery. Twenty patients with conductive or mixed hearing loss and single sided deafness were submitted to RS implantation of the BB system.

Results. Audiological assessment concerning the measurement of the functional and effective gain by pure-tone audiometry (28 dB HL and $-12.25 \mathrm{~dB}$ HL, respectively) and speech audiometry (24.7 dB HL and $-21 \mathrm{~dB}$ HL, respectively) was conducted. A high overall subjective improvement of quality of life was recorded with the Glasgow Benefit Inventory questionnaire. No major complications, such as device extrusions or other conditions requiring revision surgery, were reported during the follow-up period (median: 42 months). Conclusions. In our study, which has one of the largest cohort of patients reported in the literature, RS placement of the BB system was safe and effective. Our functional results showed comparable hearing outcomes with presigmoidal placement. The effective gain, rarely investigated in this field, may be the object of further research to improve our understanding of bone conduction mechanisms exploited by bone conduction hearing implants.
\end{abstract}

KEY WORDS: bone conduction hearing implant, Bonebridge, transcutaneous, retrosigmoidal, surgical technique

\section{RIASSUNTO}

Introduzione. Il posizionamento retrosigmoideo del sistema Bonebridge (BB) è stato introdotto per ovviare alla presenza di condizioni anatomiche e cliniche che controindichino l'alloggiamento del device in regione presigmoidea. Tuttavia, queste condizioni sfavorevoli, associate alle considerevoli dimensioni dell'impianto, possono costituire un ostacolo per i chirurghi senza esperienza nell'ambito del basi-cranio. Inoltre, in letteratura sono pochi gli studi riguardanti il posizionamento retrosigmoideo del sistema $B B$.

Metodi. Abbiamo svolto uno studio retrospettivo e multicentrico con lo scopo di analizzare i risultati chirurgici e funzionali di un'ampia popolazione di pazienti sottoposti a posizionamento retrosigmoideo del sistema BB tramite una specifica tecnica chirurgica che è stata
Received: January 15, 2020

Accepted: April 10, 2020

\author{
Correspondence \\ Pietro Canzi \\ University of Pavia, Department of Otorhinolaryn- \\ gology, IRCCS Policlinico San Matteo Foundation, \\ viale C. Golgi 19, 27100 Pavia, Italy \\ Fax +390382528184 \\ E-mail: pietro.canzi@unipv.it
}

Funding

None.

Conflict of interest

The Authors declare no conflict of interest.

\begin{abstract}
How to cite this article: Canzi P, Avato I, Beltrame M, et al. Retrosigmoidal placement of an active transcutaneous bone conduction implant: surgical and audiological perspectives in a multicentre study. Acta Otorhinolaryngol Ital 2021;41:91-99. https://doi. org/10.14639/0392-100X-N0609
\end{abstract}

(C) Società Italiana di Otorinolaringoiatria e Chirurgia Cervico-Facciale

\section{cc) (1) $(9)$}

This is an open access article distributed in accordance with the CC-BY-NC-ND (Creative Commons Attribution-NonCommercial-NoDerivatives 4.0 International) license. The article can be used by giving appropriate credit and mentioning the license, but only for non-commercial purposes and only in the original version. For further information: https:// creativecommons.org/licenses/by-nc-nd/4.0/deed.en 
sviluppata con lo scopo di superare i problemi intraoperatori relativi a questa chirurgia. Venti pazienti con ipoacusia di trasmissione o mista e affetti da sordità monolaterale sono stati sottoposti a impianto retrosigmoideo del sistema BB.

Risultati. La valutazione audiologica ha riguardato la misurazione del guadagno funzionale ed effettivo in audiometria tonale (rispettivamente pari a $28 \mathrm{~dB} H L$ e $-12.25 \mathrm{~dB} H L$ ) e audiometria vocale (rispettivamente pari a $24.7 \mathrm{~dB} H L$ e $-21 \mathrm{~dB} H L$ ). Globalmente è stato riportato un significativo miglioramento soggettivo della qualità della vita rispetto alla condizione preoperatoria, quantificato mediante la compilazione del questionario Glasgow Benefit Inventory. Non sono state riscontrate gravi complicanze o condizioni necessitanti una chirurgia di revisione durante il periodo di follow-up (mediana: 42 mesi).

Conclusioni. Nell'ambito della nostra esperienza, risultata tra le più ampie mai riportate in letteratura, il posizionamento retrosigmoideo del sistema BB si è dimostrato sicuro ed efficace. I nostri risultati funzionali hanno mostrato dati uditivi comparabili con il posizionamento presigmoideo. Il guadagno effettivo, raramente indagato in questo campo della letteratura, potrebbe essere oggetto di future ricerche al fine di migliorare la nostra comprensione dei meccanismi di conduzione ossea impiegati da questa tipologia di protesi impiantabili.

PAROLE CHIAVE: protesi impiantabile a conduzione ossea, Bonebridge, transcutaneo, retrosigmoideo, tecnica chirurgica

\section{Introduction}

In the $16^{\text {th }}$ century, Girolamo Cardano first described the transmission of sounds by bone conduction (BC) as an effective way to produce the sense of hearing ${ }^{1}$. Based on audiological principles described many centuries ago, current BC hearing implants (BCHIs) result from the impressive advances of the modern hearing industry and are used for different types of hearing impairment: conductive or mixed forms of hearing loss and single sided deafness (SSD) ${ }^{2,3}$. BCHIs are mainly divided into two different categories: skin-drive BCHIs and direct-drive BCHIs. For the first type of device, the vibrations are transmitted through intact skin, while in direct-drive BCHIs the vibrations are sent directly to the bone via a screw attached to the skull (percutaneous BCHI) or an active transducer implanted into the bone (transcutaneous BCHI) ${ }^{2}$. The active transcutaneous direct-drive systems have been developed to overcome the limits of percutaneous devices (skin irritation or infections around the screw, fixture extrusion), and to avoid the skin attenuation effects of skin-drive BCHIs. Nowadays, the Bonebridge ${ }^{\circledR}$ (Med-El, Innsbruck, Austria) (BB) is the only active transcutaneous BCHI available on the market, although another device has been in development since 2013 and is currently under regulatory review ${ }^{4,5}$. Three types of surgical placements are currently being performed for the BB housing. The most commonly used is transmastoid-presigmoid placement, in which the internal part is placed in the mastoid portion of the temporal bone (sinodural angle) ${ }^{6,7}$. The suprameatal-middle fossa placement has been proposed in patients with aural atresia and requires the drilling of the parietal bone with complete exposure of the meninges. The lack of research on direct and long-term vibrations on the dura is in alignment with the authors's recommendations for long-term follow-ups ${ }^{8}$. Retrosigmoidal (RS) placement has proven to be useful in all patients in whom anatomical or clinical conditions contraindicate a presigmoidal position ${ }^{9}$. The literature reports only limited experience concerning RS implantation of the BB system, for which surgical decision making faces many intraoperative challenges, mainly related to the device dimensions ${ }^{2,3,6-10}$. The purpose of our study was to analyse surgical and functional outcomes in a wide population of patients undergoing RS placement of the BB system by means of a surgical technique specifically developed to overcome the intraoperative issues related to this surgery.

\section{Materials and methods}

\section{Study design and participants}

A multicentre, retrospective case series study was conducted on BCHI recipients who underwent RS placement of the BB system at three Otolaryngology tertiary referral centres between January 2013 and September 2019. Approval from the local ethics committees was obtained and all patients signed informed consent agreements before treatment. All patients met the audiological criteria suggested by the manufacturer: mild to moderate conductive hearing loss (CHL) or mixed hearing loss (MHL) with pure tone average (PTA) $\mathrm{BC}$ threshold $(0.5,1,2,3$ and $4 \mathrm{kHz}) \leq 45 \mathrm{~dB} \mathrm{HL}$ and minimum PTA air bone gap (ABG) of $30 \mathrm{~dB}$, or SSD with a better ear PTA air conduction (AC) threshold $\leq 20 \mathrm{~dB}$ HL. Moreover, enrolment criteria involved:

- conditions that contraindicate a presigmoid-transmastoid approach:

- anatomical (protruding sigmoid sinus, low-lying middle fossa dura, contracted mastoid bone);

- clinical (chronical wet middle ear and mastoid cavity, previous canal wall down mastoidectomy, aural atresia scheduled for external ear reconstruction);

- failure of previous hearing rehabilitation surgery (e.g. stapedotomy, tympanoplasty);

- inadequate hearing rehabilitation with conventional hearing aids.

The preoperative assessment included a temporal bone CT scan and a brain MRI aimed at planning the surgical approach and excluding comorbidities that may contraindi- 
cate surgery or require radiological follow-up. All audiometric tests were performed with an Inventis Piano Plus ${ }^{\circledR}$ audiometer. Preoperatively, pure-tone AC threshold from 0.125 to $8.0 \mathrm{kHz}$ and pure-tone $\mathrm{BC}$ threshold from 0.25 to $4.0 \mathrm{kHz}$ were measured and the PTA $(0.5,1,2,4 \mathrm{kHz})$ was calculated. The speech reception threshold (SRT), at which $50 \%$ of the presented disyllabic words are recognised, was recorded in quiet conditions for both AC and BC. Postoperatively, a pure tone audiometry and a speech audiometry with disyllabic words in free field and quiet conditions were performed in both unaided (BB-OFF) and aided conditions (BB-ON). A noise masker by means of insert (at the nontest ear) was adopted to prevent cross hearing when necessary. As audiological outcomes, the functional gain (i.e. the difference between the postoperative unaided and aided threshold) and the effective gain (i.e. the difference between the BC threshold and the aided threshold) were evaluated by pure-tone audiometry and speech audiometry. The first fitting was planned about 1 month after surgery. Audiological follow-ups were scheduled at 3, 6, and 12 months and then yearly. The Glasgow Benefit Inventory (GBI) questionnaire was administered to each patient to evaluate items regarding the quality of life after the surgery. It consists of 18 questions, 12 of which apply to general health, 3 to physical health and 3 to social health. For each question, 5 possible answers are available (scores ranging from 1 to 5 ). Through a mathematical formula, four scores are then obtained: a total score and three partial scores (general health, physical health and social health). Each score ranging from -100 (worsening after surgery) through 0 (no change) to + 100 (improvement after surgery) ${ }^{11}$.

\section{Surgical technique}

All the surgical procedures employed the same technique, the steps of which are described below.

The conventional RS anatomical landmarks were identified to allow the positioning of the internal implanted unit (the $\mathrm{BC}$ floating mass transducer or BC-FMT) posteriorly to the sigmoid sinus and superiorly to the digastric fossa, where a regular bony surface was usually identified as the ideal location for the BC-FMT.

A retro-auricular reversed $\mathrm{C}$-shaped incision was made (4 cm-long incision) and an anteriorly pedicled C-shaped muscular-periosteal flap was harvested to enable access to the bony area located above the digastric fossa and to create a natural anatomical division between the mastoid cavity and the BB housing. The subperiosteal pouch for the location of the coil and the magnet was obtained under the flap. The probe (T-sizer) of the device was used to identify a suitable area for the BC-FMT placement. In the centre of the marked area, the cortical bone was removed by shaping a circular hole which diameter was smaller than the actual BC-FMT diameter (Fig. 1a,b).

A diamond burr was used to drill in the undercut position to safely explore the circumference of the surgical site. Careful drilling was needed close to the sigmoid sinus. If the sigmoid sinus was encountered, the circumference was enlarged step by step in a safer direction with the intent of obtaining the diameter required (Fig. 1c,d). The emissary mastoid vein was closed if intercepted.

A bony island between the BC-FMT and the dura mater was shaped in order to reach a suitable depth for the BCFMT housing when necessary. Once the bone layer was obtained, it was separated from the underlying dura mater using a freer dissector. The resulting surface could be depressed, allowing complete lodging of the BC-FMT. (Fig. 1e,f).

The T-sizer was used to verify the correct positioning of the BC-FMT, and the device was inserted and fixed with two self-tapping cortical screws. The anterior pedicle muscleperiosteal flap was reconstructed with resorbable sutures and the subcutaneous layer and the skin were then closed.

\section{Statistical analysis}

Statistical analysis were performed with $\mathrm{R}$ software ( $\mathrm{R}$ version 3.1.3, R Development Core Team, R Foundation for Statistical Computing, Wien, Austria). Descriptive statistics were calculated for all groups (the mean, standard deviation, median, minimum and maximum values). Normality of distributions was assessed with the Kolmogorov and Smirnov tests. An ANOVA test was ran to determine whether significant differences existed among the groups. The Tukey test was used post-hoc. The Kruskal Wallis test was used to assess the statistical significance of each GBI subscore. Significance for all statistical tests was predetermined at $\mathrm{p}<0.05$.

\section{Results}

A total of 20 patients ( 11 males, 9 females, median age of 47.2 years) were included in the study. 13 patients were implanted on the right side and 7 on the left side. The aetiology, type of hearing loss, and previous otologic and surgical history were investigated (Tab. I).

\section{Preoperative audiological assessment}

10 patients with CHL (50\%), 8 patients with MHL (40\%) and 2 patients with SSD (10\%) were identified; these latter two were not included in the statistical analysis of audiological outcomes because surgery was performed to obtain a contralateral routing of signal. Mean PTA (18 out of 20 patients) of the implant candidate's ear was $61.5 \mathrm{~dB} \mathrm{HL}$ 


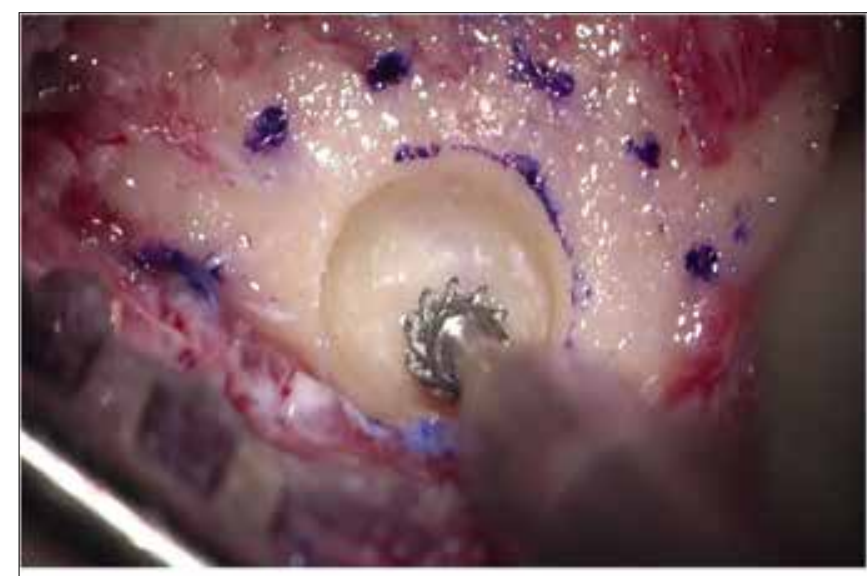

a



c

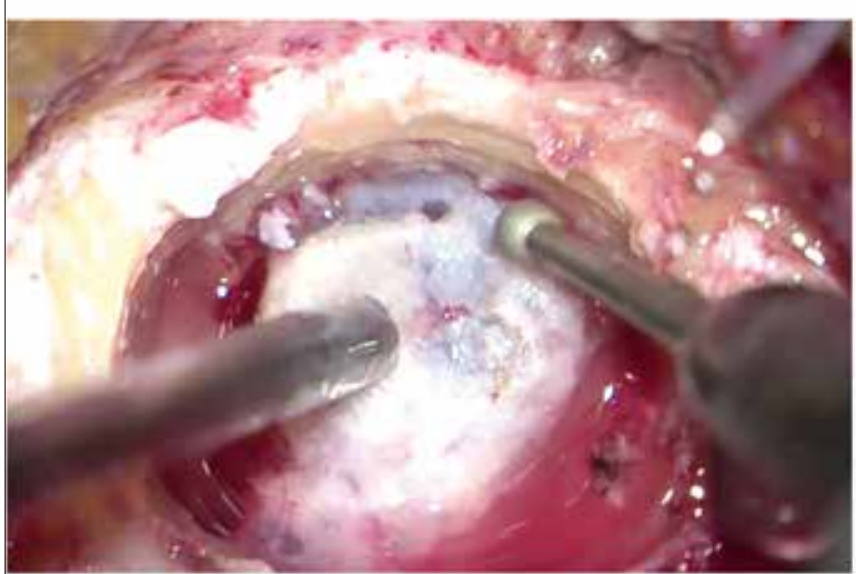

e

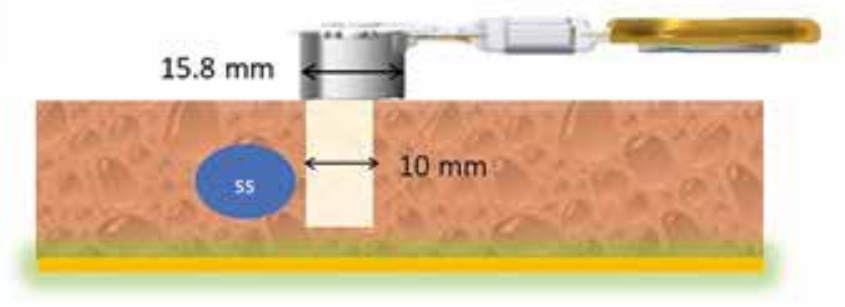

b

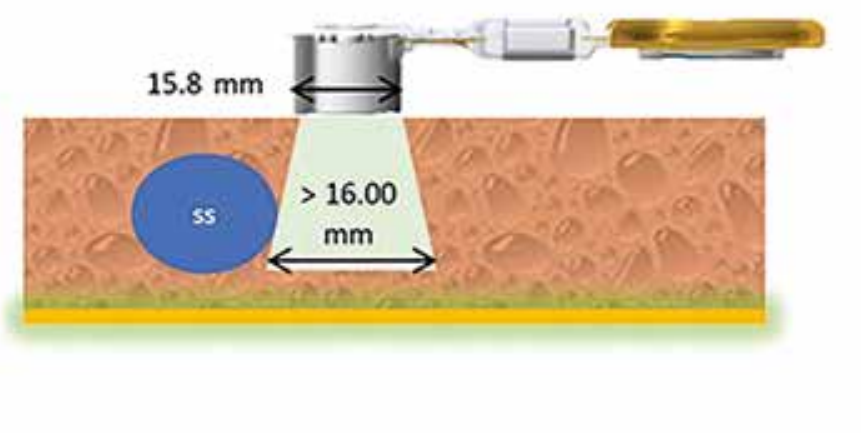

d

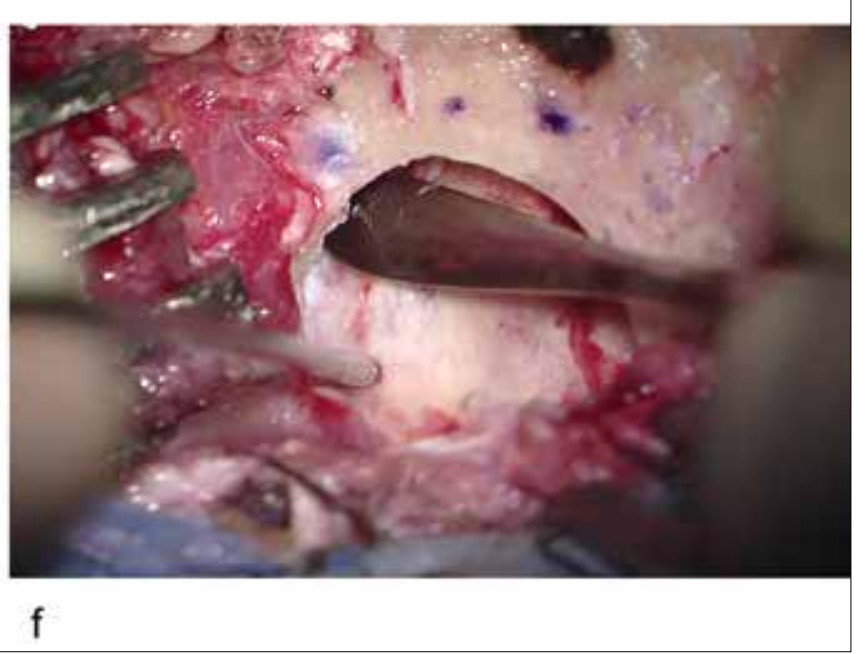

Figure 1. Intraoperative images of the surgical steps and schematic representations. A cutting burr is used for the initial drilling (a), its diameter is smaller than the actual diameter of the transducer as shown by the dotted line $(\mathbf{a}, \mathbf{b})$. An undercut drilling by means of a diamond burr is then executed to safely explore the circumference of the surgical site and to create the housing for the device (c), this process is schematically represented (SS: sigmoid sinus) (d). A bony island is sculpted to obtain a suitable depth for the housing of the device (e) and the dural layer is then detached by means of a freer dissector (f) to create a compressible surface. 
Table I. Demographic data and otologic history.

\begin{tabular}{|c|c|c|c|c|c|c|c|}
\hline Patient & Sex & Age & Hearing loss & Pathology & $\begin{array}{l}\text { Previous surgery } \\
\text { (BB side) }\end{array}$ & $\begin{array}{l}\text { Implanted } \\
\text { side }\end{array}$ & $\begin{array}{l}\text { Bony } \\
\text { island }\end{array}$ \\
\hline 1 & M & 47 & Bilateral MHL & Bilateral cholesteatoma & CWD TPL & Right & Not required \\
\hline 2 & M & 60 & Bilateral MHL & Bilateral cholesteatoma & CWD TPL & Right & Yes \\
\hline 3 & M & 23 & Bilateral CHL & $\begin{array}{l}\text { Atresia auris (BB side) + } \\
\text { cholesteatoma }\end{array}$ & None & Left & Yes \\
\hline 4 & M & 46 & Bilateral MHL & Bilateral COM & CWU TPL & Right & Yes \\
\hline 5 & $\mathrm{~F}$ & 52 & Bilateral CHL & Bilateral cholesteatoma & CWD TPL & Left & Yes \\
\hline 6 & $\mathrm{~F}$ & 45 & SSD & Cholesteatoma & CWD TPL & Right & Yes \\
\hline 7 & $\mathrm{~F}$ & 31 & Bilateral CHL & Bilateral atresia auris & None & Left & Yes \\
\hline 8 & $\mathrm{~F}$ & 49 & Bilateral MHL & Cholesteatoma (BB side) + COM & CWD TPL & Right & Yes \\
\hline 9 & M & 47 & SSD & Cholesteatoma & CWD TPL & Right & Yes \\
\hline 10 & $\mathrm{~F}$ & 61 & Bilateral MHL & Bilateral cholesteatoma & CWD TPL & Left & Yes \\
\hline 11 & M & 64 & Bilateral MHL & Bilateral COM & CWU TPL & Right & Not required \\
\hline 12 & M & 76 & MHL (BB side) + SNHL & Cholesteatoma & Lateral petrosectomy & Right & Yes \\
\hline 13 & $\mathrm{~F}$ & 67 & Bilateral MHL & Bilateral cholesteatoma & CWD TPL & Right & Yes \\
\hline 14 & $\mathrm{~F}$ & 14 & Unilateral CHL & Cholesteatoma & CWD TPL & Right & Yes \\
\hline 15 & M & 37 & Bilateral CHL & Bilateral cholesteatoma & Lateral petrosectomy & Left & Yes \\
\hline 16 & $\mathrm{~F}$ & 33 & Bilateral CHL & Bilateral otosclerosis & Stapedotomy & Right & Yes \\
\hline 17 & M & 39 & Unilateral CHL & Cholesteatoma (BB side) + COM & Lateral petrosectomy & Right & Yes \\
\hline 18 & $\mathrm{~F}$ & 47 & CHL (BB side) + MHL & Cholesteatoma (BB side) + COM & CWD TPL & Right & Yes \\
\hline 19 & M & 57 & CHL (BB side) + SNHL & Cholesteatoma (BB side) & CWD TPL & Left & Yes \\
\hline 20 & M & 48 & $\mathrm{CHL}$ & Cholesteatoma & CWUTPL & Left & No (lifts $2 \mathrm{~mm}$ ) \\
\hline
\end{tabular}

M: male; F: female; CHL: conductive hearing loss; MHL: mixed hearing loss; SNHL: sensorineural hearing loSs; SSD: single sided deafness; BB: Bonebridge; COM: chronic otitis media; CWD: canal wall down; CWU: canal wall up; TPL: tympanoplasty

(range 41.25-83.75 dB HL, SD: \pm 13.07) for AC, $20.5 \mathrm{~dB}$ HL (range 6.25-33.75 dB HL, SD: \pm 8.72) for BC. The ABG calculated on the PTA was $41 \mathrm{~dB}$ HL (range 28.75$56.25 \mathrm{~dB}$ HL, SD: \pm 7.58 ). Regarding speech audiometry on the implant candidate's ear, the mean AC SRT was 67.85 dB HL (range 55-90 dB HL, SD: \pm 13.4 ); BC SRT was $20.35 \mathrm{~dB}$ HL (range 10-40 dB HL, SD: \pm 9.49). The ABG SRT for the implanted side was $47.5 \mathrm{~dB}$ HL (range 30-70 $\mathrm{dB} \mathrm{HL}, \mathrm{SD} \pm$ 10.51) (Fig. 2).

\section{Postoperative audiological assessment}

Postoperatively, in the BB-OFF setting, AC PTA was 60.8 dB HL (range 41.25-83.75 dB HL, SD: \pm 12.22 ). The PTA threshold improved to $32.75 \mathrm{~dB}$ HL in the BB-ON setting (range 11.25-45 dB HL, SD: \pm 8.29). The mean functional gain on pure-tone audiometry was $28 \mathrm{~dB}$ HL (range 13.75$45 \mathrm{~dB}$ HL, SD: \pm 10.54$)$. Concerning speech audiometry, the mean BB-OFF SRT was $66 \mathrm{~dB}$ HL (range 40-90 dB HL, SD: \pm 13.32 ) improving up to $41.35 \mathrm{~dB}$ HL in the BB-ON setting (range 30-65 dB HL, SD: \pm 9.54). The mean functional gain as analysed via speech audiometry was $24.7 \mathrm{~dB}$ HL (range 10-36 dB HL, SD: \pm 8.74 - Fig. 3). The mean pure-tone effective gain (i.e. the mean difference between the BC PTA and the BB-ON PTA) was $-12.25 \mathrm{~dB}$ HL (range -27.5-0 dB HL, SD: \pm 8.82 ) (Fig. 3). The effective gain distribution was also selectively analysed at low $(0.25,0.5 \mathrm{kHz}), \operatorname{mid}(1,2$ $\mathrm{kHz}$ ) and high frequencies (4 kHz) and resulted in $-26.25 \mathrm{~dB}$ HL (SD: \pm 5.8$),-4.29 \mathrm{~dB}$ HL (SD: \pm 6.56 ) and $-18.57 \mathrm{~dB}$ HL (SD: \pm 9.07$)$ respectively. The mean effective gain calculated via speech audiometry was $-21 \mathrm{~dB}$ HL (range -30-0 $\mathrm{dB}$ HL, SD: \pm 8 ). During the follow-up (median: 42 months; range: 11-72 months) no worsening of the $\mathrm{BC}$ threshold occurred. About 3 months after the first fitting, a stability of the audiological gain values was observed and then confirmed at subsequent evaluations. The ANOVA and Tukey tests were ran to determine the presence of significant differences $(\mathrm{p}<0.05)$ between BB-ON thresholds and BB-OFF thresholds (functional gain) and between BB-ON thresholds and $\mathrm{BC}$ thresholds (effective gain). Specifically, pure-tone $\mathrm{BB}-\mathrm{ON}$ and BB-OFF thresholds were compared considering all frequencies between $0.25 \mathrm{kHz}$ and $4 \mathrm{kHz}$. A significant difference was found for each frequency tested $(\mathrm{p}<0.05)$. Functional gain was found significant $(\mathrm{p}<0.05)$ by speech audiometry when BB-ON SRTs were compared with BBOFF SRTs. Focusing on the effective gain analysed via puretone audiometry, a significant difference $(\mathrm{p}<0.05)$ was seen 

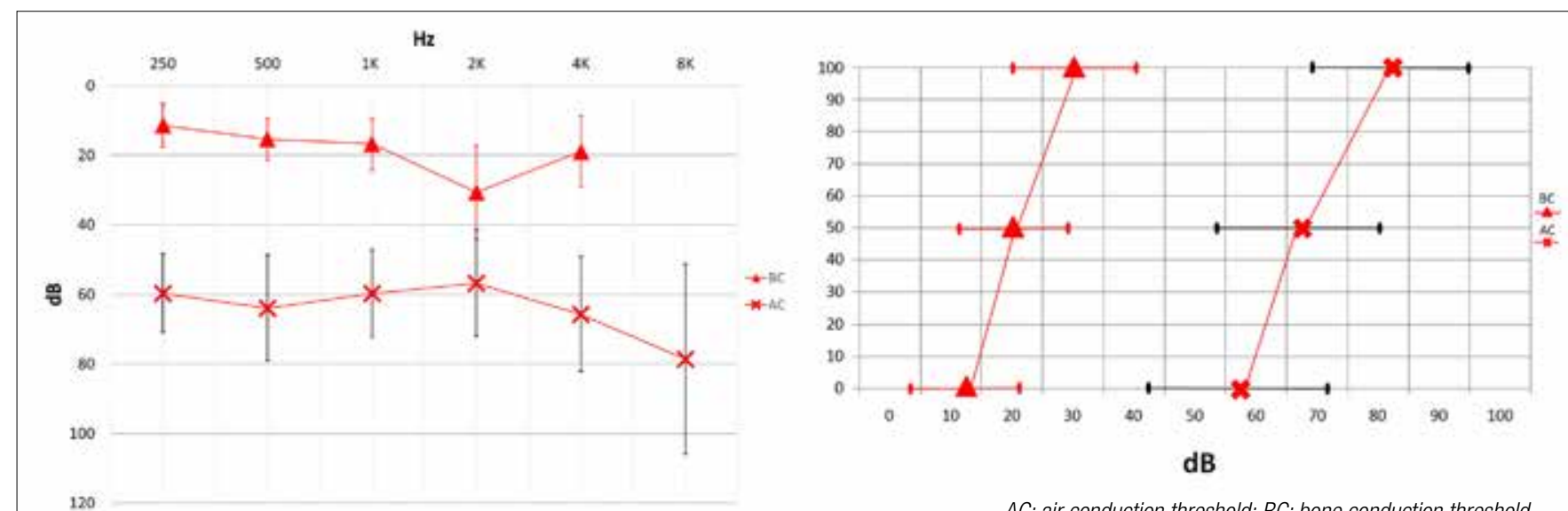

AC: air conduction threshold; $B C$ : bone conduction threshold.

Figure 2. Preoperative mean audiograms of implant candidate's ear: pure-tone audiometry (vertical bars: standard deviation) and speech audiometry (horizontal bars: standard deviation).

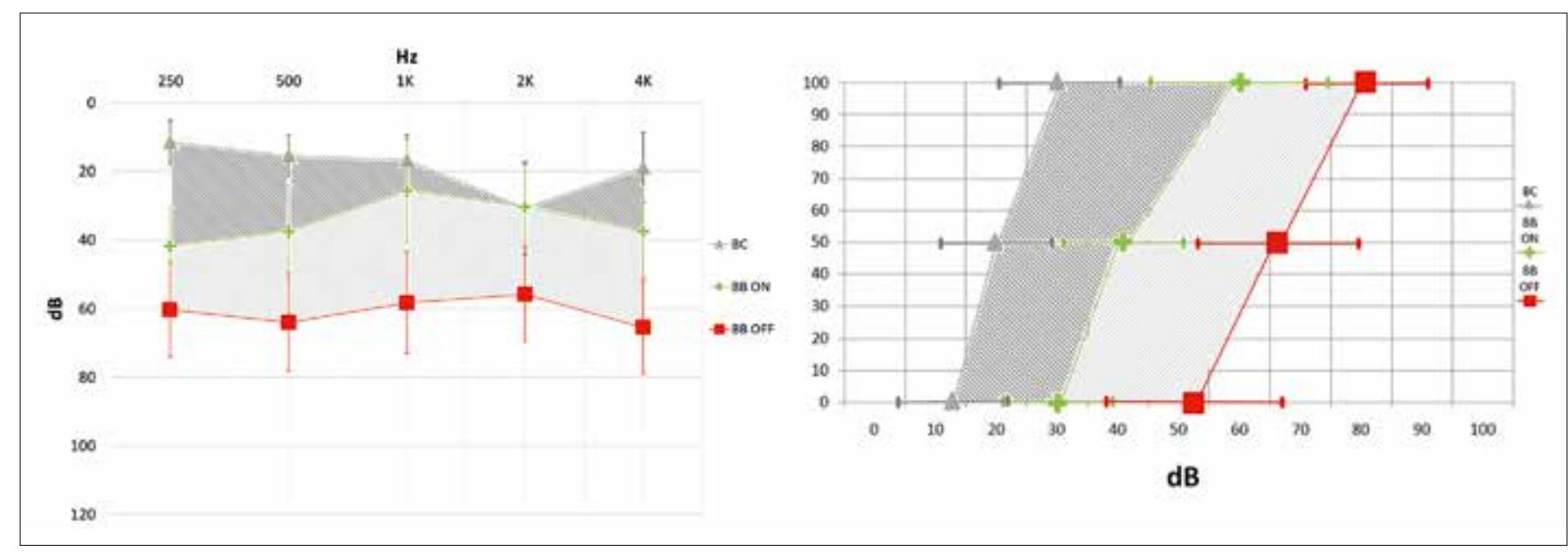

Figure 3. Mean free field aided threshold (BB-ON) compared with the free field unaided threshold (BB-OFF): pure-tone audiometry (vertical bars: standard deviation) and speech audiometry (horizontal bars: standard deviation). BC: bone conduction threshold. Light grey highlighted area: mean functional gain (i.e. the difference between the postoperative unaided and aided threshold). Dark grey highlighted area: mean effective gain (i.e. the difference between the BC threshold and the aided threshold). A noise masker by means of insert (at the contralateral ear) was adopted when necessary.

between BB-ON thresholds and $\mathrm{BC}$ thresholds at $0.25,0.5$ and $4 \mathrm{kHz}$ (Fig. 4a,c). Conversely, a significant difference was not found at 1 and $2 \mathrm{kHz}$ ( $\mathrm{p}>0.05$ ) (Fig. 4b). An overall statistically significant difference $(\mathrm{p}<0.05)$ was found when BB-ON SRTs were compared with BC thresholds (Fig. 4d).

\section{Surgery and complications}

The device was correctly placed in the designated RS surgical area in all patients and it was possible to fix the implant with both screws. Specifically, a bony island was sculpted in 17 patients (85\%) and lifts were used in 1 patient $(5 \%)$, while the implant was directly lodged in 2 patients $(10 \%)$. No major complications were observed. Minor complica- tions included a single case of dural dehiscence that was repaired with autologous fascia. Postoperative sensorineural hearing worsening or vestibular symptoms were never observed. At the time of follow-up, none of the BB recipients experienced device extrusions or other conditions requiring revision surgery.

\section{Quality of life assessment}

Concerning the GBI questionnaire, descriptive statistics are showed in Table II. Patients showed general, physical and social health gain $(\mathrm{p}<0.05$; Fig. 5) and no significant differences were reported among the various subcategories $(\mathrm{p}>0.05)$. 


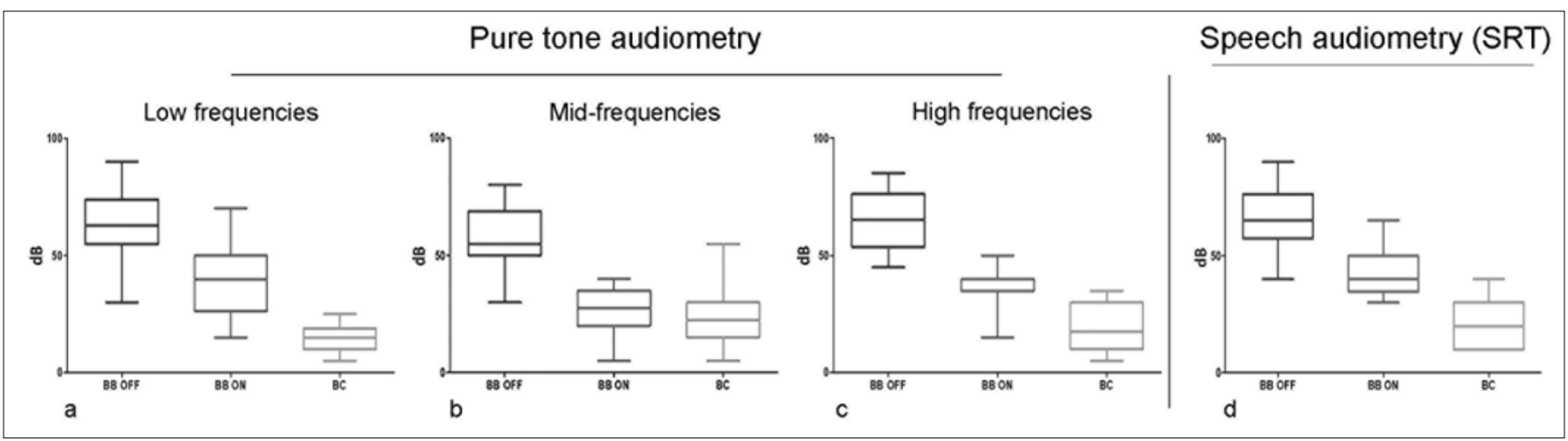

Figure 4. ANOVA test applied to compare the free field aided thresholds (BB-ON) with the free field unaided thresholds (BB-OFF) and with bone conduction (BC) thresholds. a) Pure-tone audiometry - low frequencies b) Pure-tone audiometry - mid frequencies; c) Pure-tone audiometry - high frequencies; d) Speech audiometry - speech recognition threshold (SRT). All graphs show a significant difference $(p<0.05)$ when the BB-ON thresholds are compared with the BB-OFF thresholds. All graphs show a significant difference $(\mathrm{p}<0.05)$ when the BB-ON thresholds are compared with the BC thresholds with the exception of the midfrequencies graph. Vertical bars: standard deviation.

Table II. Glasgow Benefit Inventory descriptive statistics.

\begin{tabular}{|c|c|c|c|c|c|}
\hline & Mean & SD & Min & Median & Max \\
\hline Total score & 49.40 & 19.54 & 10 & 55.5 & 83 \\
\hline $\begin{array}{l}\text { General } \\
\text { health }\end{array}$ & 55.65 & 17.88 & 15 & 58.5 & 92 \\
\hline $\begin{array}{l}\text { Physical } \\
\text { health }\end{array}$ & 41.70 & 27.63 & -15 & 42 & 84 \\
\hline Social health & 34.60 & 32.09 & -33 & 50 & 80 \\
\hline
\end{tabular}

SD: standard deviation.

\section{Discussion}

Our study presents one of the largest samples of patients submitted to RS implantation of the BB system reported in literature. The sample is highly homogeneous in terms of surgical technique and audiological assessment. First described by Sprinzl et al. in a European multicentre study ${ }^{12}$, RS placement has been advocated in case of unfavourable anatomical or clinical conditions which contraindicate the presigmoidal position ${ }^{9,13,14}$. However, these disadvantageous conditions combined with the considerable dimensions of the internal implanted unit $(8.7 \mathrm{~mm}$ in thickness and $15.8 \mathrm{~mm}$ in diameter) and with the topography of the anatomical area addressed to the BC-FMT housing, make this surgical procedure challenging ${ }^{7,15-17}$. In alignment with data from the literature, medical history of previous middle ear surgery represented the main eligibility criteria for a RS position ${ }^{9}$ in our study. The harvesting of an anteriorly pedicled muscular-periosteal flap was developed to prevent possible contaminations from the mastoid cavity and middle ear towards the site of implantation. The surgical technique was designed to obtain an adequate bony bed for the BC-FMT housing, while avoiding hazardous

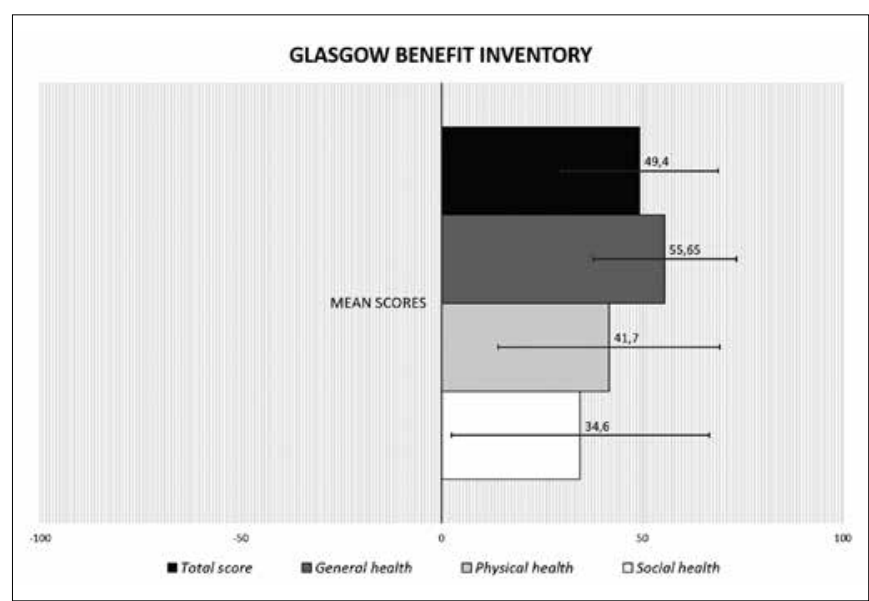

Figure 5. Results of the Glasgow Benefit Inventory (GBI) questionnaire. The histogram provides a graphic representation of the quality of life after surgery reporting the mean GBI total and partial scores (horizontal bars: standard deviation). Scores can range from - 100 (worsening after surgery) through 0 (no change) to +100 (improvement after surgery). A significant improvement $(p<0.05)$ is shown for each GBI score and no significant differences are reported among the various subcategories $(p>0.05)$.

drilling (especially close to the sigmoid sinus). It also prevents over-extension of the drilling surface which could compromise fixation of screws. In all $\mathrm{BB}$ recipients, the surgical procedure was successfully performed with a complete lodging of the BC-FMT and with its fixation with two self-tapping screws. None of the patients required revision surgery or BB explantation. A bony island was sculpted in $85 \%$ of patients, allowing adequate BC-FMT housing and concurrent protection of the dura from major complications both intra- and postoperatively. Brkic et al. ${ }^{18}$ recently reported one of the largest studies of patients submitted to BB implantation, analysed over a 6-year follow-up period. In 
their experience, the authors observed an overall complication rate of $9.4 \%$ including 5 cases of explantation. Interestingly, 3 of these implants were positioned in a radical cavity, which was subsequently compromised by postoperative infections. According to the authors, a presigmoidal approach is to be preferred even in patients with history of previous radical cavities because of anatomical factors limiting RS placement. Furthermore, the same tertiary referral centre published a previous study of 19 patients in which the BC-FMT was directly coupled to the dura or sinus (7 RS placements, 12 presigmoidal/middle fossa placements). Although no adverse events were reported, the authors clarified that the risks of direct sinus/dura compression are not yet clear ${ }^{19}$.

In our experience, the surgical technique was designed to overcome the abovementioned issues and to reduce the possibility of revision surgery or long-term untoward events. Considering audiological findings, all patients enrolled met the preoperative recommended criteria: specifically, mean BC PTA was $20.5 \mathrm{~dB}$, almost $25 \mathrm{~dB}$ lower than the manufacturer's indications. The effectiveness of BCHI was investigated by means of two audiological measurements: functional and effective gain. The mean PTA functional gain was found to be $28 \mathrm{~dB} \mathrm{HL}$, consistent with the results reported in the two largest series of RS implanted patients (28.9 $\mathrm{dB}$ and $28 \mathrm{~dB}$ in Ihler et al. ${ }^{20}$ and Loader et al. ${ }^{14}$ respectively). With regards to presigmoidal placement, our data did not reveal a significant difference in terms of mean functional gain (Gerdes et al. ${ }^{21} 27.5 \mathrm{~dB}$; Riss et al. ${ }^{22} 28.8$ dB). Although debated in literature, superior audiological effectiveness cannot be assessed using currently published data when the two BC-FMT surgical placements are compared ${ }^{14,19,23,24}$. The effective gain is considered expression of the relationship between the threshold in aided condition and the patient's cochlear reserve. Defined as the difference between the $\mathrm{BC}$ threshold and the aided threshold, the effective gain may result in negative values and if positive, indicates ABG overclosure. This parameter was previously measured by Donnelly et al. ${ }^{25}$ to evaluate the effectiveness of different types of active middle ear implants and by van Barneveld et al. ${ }^{26}$ to define fitting ranges for BC devices. To the best of our knowledge, only one study has reported this parameter in $\mathrm{BCHI}$ recipients ${ }^{18}$, although it was not object of further analysis. In our experience, the mean pure-tone effective gain was $-12.25 \mathrm{~dB}$ HL, although it showed a different statistical distribution when selectively analysed at low, mid and high frequencies. In particular, the highest values were measured at $1-2 \mathrm{kHz}(-4.29 \mathrm{~dB} \mathrm{HL})$ where a significant difference between the BB-ON thresholds and the BC thresholds was not found. These observations, apparently, do not relate to power output issues. What seems to limit the BB fitting range on certain frequencies are unpleasant sound distortions and annoying vibratory perceptions ${ }^{26}$. The RS placement itself, does not seem to be related to these findings, since our audiological results have shown to be comparable with current literature data for presigmoid positioning. Furthermore, a significant improvement in the quality of life was recorded in all patients as suggested by the total and partial GBI scores. We are, nonetheless, aware that some concerns regarding our study may arise. The retrospective and multicentric nature of the study may be considered a limitation in terms of heterogeneity of the series. However, the adoption of common enrolment criteria and a standardised surgical technique and the uniformity of data analysis minimise this bias. Additionally, the introduction of an uncommonly used audiological measurement such as the effective gain may preclude comparison with the current literature.

\section{Conclusions}

RS placement of the BB system was seen to be safe and effective, thus constituting in a valid surgical alternative when the presigmoidal position is not advised. However, it may represent a challenge, especially for surgeons with no skull base experience. The surgical technique introduced was developed to define the main surgical steps of RS placement in order to obtain a complete lodging of the internal implanted unit, avoiding untoward events both intraand postoperatively, even after long-term follow-up. Our functional results show comparable hearing outcomes with presigmoidal placement, in contrast to authors who argue a greater efficacy of one of the two positions. The effective gain, rarely investigated in this field of literature, may be object of future research to improve our understanding of BC mechanisms exploited by the BCHIs.

\section{References}

1 Berger KW. Early bone conduction hearing aid devices. Arch Otolaryngol 1976;102:315-8. https://doi.org/10.1001/archotol.1976.00780100101017

2 Reinfeldt S, Håkansson B, Taghavi H, et al. New developments in bone-conduction hearing implants: a review. Med Devices (Auckl) 2015;8:79-93. https://doi.org/10.2147/MDER.S39691

3 Canale A, Boggio V, Albera A, et al. A new bone conduction hearing aid to predict hearing outcome with an active implanted device. Eur Arch Otorhinolaryngol 2019;276:2165-70. https://doi.org/10.1007/ s00405-019-05450-4

4 Eeg-Olofsson M, Håkansson B, Reinfeldt S, et al. The bone conduction implant - first implantation, surgical and audiologic aspects. Otol Neurotol 2013;35:679-85. https://doi.org/10.1097/ MAO.0000000000000203

5 Håkansson B, Reinfeldt S, Persson AC, et al. The bone conduction 
implant - a review and 1-year follow-up. Int J Audiol 2019;58:94555. https://doi.org/10.1080/14992027.2019.1657243

6 Sprinzl GM, Wolf-Magele A. The Bonebridge Bone Conduction Hearing Implant: indication criteria, surgery and a systematic review of the literature. Clin Otolaryngol 2016;41:131-43. https://doi. org/10.1111/coa.12484

7 Wimmer W, Gerber N, Guignard J, et al. Topographic bone thickness maps for Bonebridge implantations. Eur Arch Otorhinolaryngol 2015;272:1651-8. https://doi.org/10.1007/s00405-014-2976-8

8 Der C, Bravo-Torres S, Pons N. Active transcutaneous bone conduction implant: middle fossa placement technique in children with bilateral microtia and external auditory canal atresia. Otol Neurotol 2018;39:342-8. https://doi.org/10.1097/ MAO.0000000000001809

9 Lassaletta L, Sanchez-Cuadrado I, Muñoz E, et al. Retrosigmoid implantation of an active bone conduction stimulator in a patient with chronic otitis media. Auris Nasus Larynx 2014;41:84-7. https://doi. org/10.1016/j.anl.2013.04.004

10 Barbara M, Perotti M, Gioia B, et al. Transcutaneous bone-conduction hearing device: audiological and surgical aspects in a first series of patients with mixed hearing loss. Acta Otolaryngol 2013;133:105864. https://doi.org/10.3109/00016489.2013.799293

11 Robinson K, Gatehouse S, Browning GG. Measuring patient benefit from otorhinolaryngological surgery and therapy. Ann Otol Rhinol Laryngol 1996;105:415-22. https://doi. org/10.1177/000348949610500601

12 Sprinzl G, Lenarz T, Ernst A, et al. First European multicenter results with a new transcutaneous bone conduction hearing implant system: short-term safety and efficacy. Otol Neurotol 2013;34:1076-83. https://doi.org/10.1097/MAO.0b013e31828bb541

13 Lassaletta L, Calvino M, Zernotti M, et al. Postoperative pain in patients undergoing a transcutaneous active bone conduction implant (Bonebridge). Eur Arch Otorhinolaryngol 2016;273:4103-10. https:// doi.org/10.1007/s00405-016-3972-y

14 Loader B, Sterrer E, Reichmayr C, et al. Direct comparison of mastoidal and retrosigmoidal placement of a transcutaneous bone conduction device after canal wall down tympanoplasty. Clin Otolaryngol 2018;43:1603-6. https://doi.org/10.1111/coa.13187

15 Bianchin G, Bonali M, Russo M, et al. Active bone conduction system: outcomes with the Bonebridge transcutaneous device. ORL 2015;77:17-26. https://doi.org/10.1159/000371425
16 Canzi P, Marconi S, Manfrin M, et al. From CT scanning to 3D printing technology: a new method for the preoperative planning of a transcutaneous bone-conduction hearing device. Acta Otorhinolaryngol Ital 2018;38:251-6. https://doi.org/10.14639/0392-100X-1625

17 Law EKC, Bhatia KSS, Tsang WSS, et al. CT pre-operative planning of a new semi-implantable bone conduction hearing device. Eur Radiol 2016;26:1686-95. https://doi.org/10.1007/s00330-015-3983-x

18 Brkic FF, Riss D, Scheuba K, et al. Medical, technical and audiological outcomes of hearing rehabilitation with the bonebridge transcutaneous bone-conduction implant: a single-center experience. J Clin Med 2019;8:1614. https://doi.org/10.3390/jcm8101614

19 Vyskocil E, Riss D, Arnoldner C, et al. Dura and sinus compression with a transcutaneous bone conduction device - hearing outcomes and safety in 38 patients. Clin Otolaryngol 2017;42:1033-8. https:// doi.org/10.1111/coa.12793

20 Ihler F, Blum J, Berger MU, et al. The prediction of speech recognition in noise with a semi-implantable bone conduction hearing system by external bone conduction stimulation with headband: a prospective study. Trends Hear 2016;20:1-12. https://doi. org/10.1177/2331216516669330

21 Gerdes T, Salcher RB, Schwab B, et al. Comparison of audiological results between a transcutaneous and a percutaneous bone conduction instrument in conductive hearing loss. Otol Neurotol 2016;37:685-91. https://doi.org/10.1097/MAO.0000000000001010

22 Riss D, Arnoldner C, Baumgartner WD, et al. Indication criteria and outcomes with the Bonebridge transcutaneous bone-conduction implant. Laryngoscope 2014;124:2802-6. https://doi.org/10.1002/ lary. 24832

23 Salcher R, Zimmermann D, Giere T, et al. Audiological results in SSD with an active transcutaneous bone conduction implant at a retrosigmoidal position. Otol Neurotol 2017;38:642-7. https://doi. org/10.1097/MAO.0000000000001394

24 Schmerber S, Deguine O, Marx M, et al. Safety and effectiveness of the Bonebridge transcutaneous active direct-drive bone-conduction hearing implant at 1-year device use. Eur Arch Otorhinolaryngol 2017;274:1835-51. https://doi.org/10.1007/s00405-016-4228-6

25 Donnelly NP, Pennings RJE. Hearing rehabilitation with active middle ear implants. Adv Otorhinolaryngol 2018;81:43-56. https://doi. org/10.1159/000485529

26 Van Barneveld DCPBM, Kok HJW, Noten JFP, et al. Determining fitting ranges of various bone conduction hearing aids. Clin Otolaryngol 2018;43:68-75. https://doi.org/10.1111/coa.12901 